\title{
El baile de las que sobran, el contrato como estrategia de adaptación en Loco Afán.
}

\section{Resumen}

A partir de la oposición entre los conceptos de masoquismo y sadismo, en este trabajo se realiza un análisis de cuatro textos de Loco afán: crónicas de sidario (1996) de Pedro Lemebel: "La noche de los visones", "La Regine de Aluminios el Mono", "Atada a un granito de arena" y "Su ronca risa loca". A partir de las etimologías literarias de ambos conceptos, propongo que las nociones de masoquismo y sadismo describen la manera en que se establecen lazos sociales. En breve, si el masoquismo implica relaciones horizontales (contractuales), el sadismo implica relaciones verticales. Sobre esta base conceptual, el objetivo general del trabajo es identificar el tipo de vínculo social (¿masoquista o sádico?) que establecen las travestis presentes en las crónicas de Loco afán. Se propone que en las crónicas de Lemebel, el lazo es masoquista y no sádico pues sus personajes protagónicos (miembros de minorías sexuales y políticas) saturan su posición de exclusión social a través del comercio sexual. Al saberse excluidos, estos personajes desarrollan una relación masoquista en el trato con el otro (cliente ocasional). En suma, en las crónicas de Lemebel el carácter contractual del lazo masoquista que establecen en sus prácticas de comercio sexual les permite construir una fantasía de legitimación de su condición sexual: la forma en que se produce el contrato en las crónicas siempre involucra el cuerpo. Se concluye que es este tipo de prácticas el que, paradójicamente, excluye a la travesti de la sociedad en primera instancia (por reflejar superficialmente la condición sexual que tiene), y al mismo tiempo, es la herramienta que utiliza para poder construir su fantasía e inscribirse en el tejido social.

Palabras claves

masoquismo, contrato, travesti, cuerpo, Pedro Lemebel.

\begin{abstract}
From the opposition between the concepts of masochism and sadism, this works analyze four chronicles of Loco afán: crónicas de sidario (1996) of Pedro Lemebel: "La noche de los visones", "La Regine de Aluminios el Mono", "Atada a un granito de arena" y "Su ronca risa loca". Beginning from the literary etymologies of both concepts, I proposed that masochism and sadism describe how the social bonds are stablished. In short, masochism implies
\end{abstract}


horizontal relationships (contracts) while sadism implies verticals. From this assumption, the general purpose of this work is to identify the kind of social bond (masochist or sadist) that the transvestites make in the chronicles of Loco Afán. I proposed that in the selected works the bond is masochist because the protagonist of the stories (members of a minor sexual and sociopolitical class) saturate their position of social exclusion through sex trade. Being aware of their marginalization, the characters develop a masochist relationship with others (occasional client). In sum, in Lemebel chronicles the contractual characteristic of the masochist bond produced by their characters through their sex trade practices allowed them to create a fantasy of legitimation regarding their sexual condition: the way the contract is produced in the texts always involves the body. It is concluded, paradoxically, that this practices that excludes the transvestites from society in first instance, at the same time, is the tool that is used to build their fantasy and inscribed themselves in the social network.

Keywords masochism, contract, transvestite, body, Pedro Lemebel

\section{Sade, Sacher-Masoch y el diagnóstico de la perversion.}

Los conceptos de sadismo y masoquismo son ejemplo de como la literatura afecta a la sociedad. Estos reflejan como la ficción alimenta el imaginario social, generando (en este caso) conductas que han devenido en patologías. Por un lado, el origen etimológico de ambas nociones debe su nacimiento a la literatura. Respectivamente cada uno de los conceptos mencionados hace alusión a un escritor: el primero al Marqués de Sade (17401814), mientras que el segundo a Leopold von Sacher-Masoch (1836-1895). Más aún, estas "perversiones"1 tienen en parte el origen de su fundamentación sintomática en la obra de los autores mencionados. Ambos logran materializar en su escritura la forma en que se constituyen cada una de las perversiones y es por

\footnotetext{
1 "Desviación con respecto al acto sexual 'normal', definido como coito dirigido a obtener el orgasmo por penetración genital, con una persona del sexo opuesto... De un modo más general, se designa como perversión el conjunto del comportamiento psicosexual que acompaña a tales atiplas [orgasmo a través de objetos, zonas corporales no genitales y/o condiciones extrínsecas] en la obtención del placer sexual." (Laplanche y Pontalis 272). Se infiere que el masoquismo y el sadismo pertenecen a la categoría de perversión debido a que la obtención del placer sexual se liga a otros factores aparte del coito genital.
} 
esta razón que la denominación que recibieron lleva el nombre del autor que la describe.

La importancia de este hecho yace en definir de qué forma se constituye cada una de estas ideas de manera particular y cómo se renuevan en la escritura. Esto implica que cada una de las nociones se considera completa en sí misma y no como dos polos complementarios, es decir, como se ha representado en el concepto de sadomasoquismo. A través de este se ha tratado de describir que ambas perversiones son capaces de coexistir en un mismo sujeto. Sin embargo, cada una de las perversiones describe una forma diferente de interactuar con el deseo. En palabras de Deleuze (1991), el sadismo y el masoquismo son confundidos cuando son tratados como entes abstractos aislados de su universo específico: "Once they have been cut off from their Umwelt and stripped of their flesh and blood, it seems natural that they should fit with each other" (42).

Es en lo que Deleuze denomina "pornological literature" en donde ambas ideas pueden ser entendidas desde una perspectiva retórica. El concepto deleuzeano hace referencia al tipo de escritura que busca llevar el lenguaje a sus límites, a un no-lenguaje (22). Sin embargo, el autor señala que "this task can only be accomplished by an internal spliting of language: the imperative and descriptive functions must trascend itself toward a higher function, the personal element turning by reflection upon itself into the impersonal" (22). En cada uno de los escritores señalados (Sade y Sacher-Masoch) se genera esto, pero de maneras diferentes; "In Sade the... function of language trascends itself towards a pure demonstrative, instituting function, and in Masoch toward a dialectical, mythical and persuasive function" (23).

La obra de Sade y Sacher-Masoch ilustran respectivamente cada una de las perversiones. En Justine o los infortunios de la virtud (1791) se describe a lo largo de la obra como la protagonista (Justine) cae constantemente en las garras de diversos personajes que representan al sujeto sádico. Ejemplo de esto lo encontramos cuando discute con el monje Clement del convento de Santa María de los Bosques y este señala: 
no, no cesaré de repetirlo, es completamente inútil que un goce sea compartido para ser vivo; y para que este tipo de placer sea tan excitante como puede llegar a ser, es, por el contrario, muy esencial que el hombre solo goce a expensas de la mujer, que tome de ella (sea cual fuere la sensación que ella experimente) todo cuanto pueda incrementar la voluptuosidad que él quiere disfrutar. (Sade 190)

Relacionado al aspecto demostrativo de la escritura de Sade, la intención del autor es demostrar que la razón es una forma de violencia. En este sentido, la razón no tiene que ser compartida por la contraparte (Justine) al igual que el placer tampoco lo es (Deleuze 18). La representación repetitiva de la violencia por parte del sujeto sádico de la obra de Sade tiene como función demostrar una nueva visión de mundo. Es por esto que el erotismo que caracteriza sus textos tiene una función fundamental, "eroticism is able to act as a mirror to the world by reflecting its excesses, drawing out its violence... the words of this literature create a counter-language which has a direct impact on the senses" (37). La intención de Sade radica en demostrar la forma en que se ha construido la historia del ser humano hasta su época, la Revolución Francesa. La forma de hacer esto estará caracterizada por reflejar perversamente lo que la caracteriza. (37)

Por otro lado, La venus de las pieles (1870) de Sacher-Masoch describe de qué manera se constituye el masoquismo. En esta perversión el acuerdo entre las partes es la característica principal: "El señor Severino de Kusiemski deja de ser, desde este día, el prometido de la señora Wanda de Dunaiew y renuncia a todos los derechos que le procuraba su calidad de amante. Se compromete, en cambio, bajo palabra de hombre y de gentilhombre, a ser, de ahora en adelante, el esclavo de esta señora hasta que ella decida devolverle la libertad" (Sacher-Masoch 86). Esta parte del contrato que establecen los protagonistas de la novela refleja de qué manera el acuerdo es el paso previo, el cual estipula las condiciones que definen 
la relación masoquista. Es a través de un contrato entonces en que ambas partes llegan a un consenso, a diferencia de la relación sádica en donde no existe un tal.

Deleuze relaciona al masoquismo con este término. Al hablar de este tipo de vínculo señala que, "They must be regulated by contracts that formalize and verbalize the behavior of the partners. Everything must be stated, promised, announced and carefully described before being accomplished" (18). Las travestis de las crónicas lemebelianas desarrollan este tipo de vínculo, por ejemplo en "Su ronca risa loca", donde los "regateos comerciales" para establecer cuáles son las "acrobacias y piruetas" deseadas, reflejan como el lazo se expresa en la escritura de Lemebel. A lo largo de este trabajo analizaré de qué forma el contrato aparece como táctica para establecer relaciones intersubjetivas entre los personajes.

Deleuze describe que el masoquista tiene un proceso de renegación ${ }^{2}$ extensivo, el cual afecta al deseo sexual: el placer es pospuesto por el máximo tiempo posible y es por esto que es renegado (33). El masoquista establece una suspensión del placer y en este sentido, en la escritura de Sacher-Masoch, toda potencial obscenidad es suspendida (renegada) desplazando las descripciones hacia otros objetos (34). Deleuze desprende de esto una de las características de la performance del masoquista, "its theatricality is a peculiar form of cruelty in the woman torturer: the cruelty of the Ideal, the specific freezing point, the point at which idealism is realized" (55). Esta mujer, caracterizada por su frialdad y silencio, es la que Deleuze identifica con la madre oral; figura que se posiciona entre la madre uterina y la madre edípica, resolviendo el problema de los dos opuestos (mujer griega y mujer sádica, respectivamente) para poder concretar la fantasía masoquista (ibid) ${ }^{3}$. En este escenario el uso de la fantasía por parte del

\footnotetext{
${ }^{2}$ Traduzco el concepto de "disavowal" utilizado por Deleuze como "renegación" basándome en la definición y traducción presente en el Diccionario de psicoanálisis (2004) de Laplanche y Pontalis. En este, renegación se define como: "modo de defensa consistente en que el sujeto rehúsa reconocer la realidad de una percepción traumatizante, principalmente la ausencia de pene en la mujer. Este mecanismo fue especialmente invocado por Freud para explicar el fetichismo y las psicosis." (363)

${ }^{3}$ Profundizando al respecto, Deleuze señala que se espera quela madre oral, como ideal de la mujer del masoquismo, asuma todas las funciones de las otras figuras femeninas. En este acto, la madre oral las transforma y sublima (63). Debido a esto, la figura del padre es cancelada y a sus
} 
sujeto masoquista adquiere una intención particular: consiste en neutralizar la realidad y contener lo ideal dentro de la fantasia. (73)

La intención entonces de la suspensión radica en la protección de este momento: "the masochistic hero must evolve a complex strategy to protect his world of fantasy and symbols, and toward off the hallucinatory inroads of reality... This procedure which... is constantly used in masochism, is the contract." (65). En el sujeto masoquista este adquiere una connotación especial; el contrato masoquista genera un tipo de ley que lo lleva al ritual, esto debido a que es este tipo de actividad que resume su fantasía (Deleuze 94). Es en la ley creada por el contrato en donde el masoquista construye su deseo. Para esto, aparece la cualidad pedagógica del masoquista, este educa a su contraparte para poder constituir su fantasía. Suspensión, fantasía, contrato y educación son cualidades del masoquista que tendrán la función de crear un contexto donde pueda satisfacer su deseo.

Carole Pateman en The Sexual Contract (1988) señala que un contrato concibe derechos políticos conformando relaciones que se establecen en la forma de dominación y subordinación entre las partes (8). El dilema está en que estas relaciones se establecen con el uso de la libertad individual de los sujetos que conforman un contrato. Pateman ejemplifica este hecho con dos ejemplos: la relación entre capitalista y obrero, y entre marido y mujer, en donde los primeros tienen el dominio sobre el segundo. Un segundo aspecto sobre la noción de contrato es la idea de que introduce a la sociedad una forma moderna de ley (16), donde los contratos son un eje fundamental del patriarcalismo moderno, característico de las sociedades capitalistas (25).

El concepto de contrato surge en la Modernidad y funciona como base para las relaciones que se establecen en las sociedades capitalistas. Pateman señala que en la teoría, los contratos se conciben en la sociedad moderna como

partes y funciones son distribuidas entre las tres mujeres; las cuales finalmente deberán pasar a la madre oral. "In short the three women constitute a symbolic order in which and through the father is abolished in advance" (ibid). 
la doctrina de emancipación por excelencia; estos funcionan como la concretización de la idea de libertad universal es un principio en las sociedades modernas (39). La libertad del individuo radica en su capacidad de ser el dueño de su propiedad; noción que abarca la idea de ser propietario de su persona y de sus habilidades, las cuales puede poner a disposición a través de un contrato (55). Cuando en la práctica esto se realiza, por un lado, los individuos generan relaciones sociales entre ellos, por otro, se produce que una de las partes involucradas pasa a ser subordinado del otro. Pateman señala que lo único que separa esta idea de la de un contrato esclavista es el postulado de la igualdad natural de las personas, lo cual se refleja en que la seguridad de la propiedad esta resguardada (60).

En síntesis, para el análisis en este trabajo mi interés radica en diferenciar ambos conceptos como categorías retóricas que definen la manera en que se constituyen dos tipos de $\operatorname{lazos}^{4}$ : con el sadismo se forja uno caracterizado por la verticalidad entre quienes lo conforman, es decir, se genera una jerarquía entre las partes. Por otro lado, el término masoquismo constituye un lazo horizontal, ambas partes acuerdan como se manifiesta la relación ${ }^{5}$. Esto implica alejarse de la perspectiva que tiene la sicología de estas perversiones ${ }^{6}$, esto es, como práctica sexual no heterosexual. Debido a esto, la patología sadomasoquismo queda obsoleta del análisis realizado; lo que nos lleva al postulado que desarrollaremos

\footnotetext{
4 Tomo el concepto de Scheff (1997), el lazo social se define como la manera en que la personalidad, el comportamiento y las actitudes de las personas surgen de las relaciones que tienen con otros. El tipo de lazo que se construye adquiere una gran importancia al definir al sujeto dentro de la sociedad, el rol de este dependerá del tipo de lazo que produzca.

${ }^{5}$ Claramente hay una imposibilidad en establecer un solo tipo de lazo (sádico o masoquista), pero si existe una predominancia y la intención de generar uno u otro.

${ }^{6}$ Especialmente de los orígenes de estos conceptos como en los escritos de Kraft-Ebbing y de las ideas de Freud, por ejemplo, cuando refiere que "El sadismo y el masoquismo ocupan, entre las perversiones, un lugar especial. La actividad y la pasividad, que forman sus características fundamentales y opuestas, son constitutivas de la vida sexual en general" (citado en Laplanche y Pontalis 391). Esto porque al entender que el masoquista establece un lazo contractual, nos alejamos de la perspectiva de considerarlo como un sujeto pasivo.
} 
más adelante con el análisis de las crónicas de Lemebel: las travestis ${ }^{7}$ establecen relaciones contractuales con un otro. ${ }^{8}$

\section{Esas locas masoquistas, el contrato de la supervivencia.}

\begin{abstract}
¿No habrá un maricón en alguna esquina desequilibrando el futuro de su hombre nuevo? Pedro Lemebel
\end{abstract}

Los textos que analizaré para describir como se constituye el lazo masoquista entre sus personajes pertenecen al libro Loco afán: crónicas de sidario (1996). Estos son: "La noche de los visones", contextualizada en el fin de año de 1972 en la fiesta de una travesti, la Palma. Invitando a travestis de los estratos socioeconómicos populares y acomodados se narra el ambiente de tensión política que reina en el país, representada en cada uno de estos grupos. La crónica funciona como un vaticinio de lo que ocurrirá en el año 1973: la caída de la Unidad Popular y el comienzo de la dictadura militar. Ligando este suceso la historia continua relatando el destino de tres travestis infectadas con SIDA (para el autor, la dictadura militar se relaciona estrechamente con la llegada de este virus al país ${ }^{9}$ ): la Palma, la Pilola Alessandri y la Chumilou.

La segunda crónica, "La Regine de Aluminios el Mono" cuenta la historia de Regine, travesti dueña de un prostíbulo clandestino donde llegan las patrullas de la dictadura militar a solicitar sus servicios. De forma paralela se narra la

\footnotetext{
${ }^{7}$ En Escritura/Travestismo (1969) Sarduy reflexiona sobre la aparición del travesti en la creación literaria. Señala que el postiche travesti no sólo es la artificialidad en la inversión sexual, sino que también se da en el lenguaje utilizado (1147-1149). Éste permite ocultar a través de la simbiosis de los géneros que se da en el travesti el conflicto de la historia.

${ }^{8}$ El análisis que viene a continuación se relaciona con un trabajo publicado en el Vol. $1 \mathrm{n}^{\circ} 2 \mathrm{de}$ Catedral Tomada, "Construcción de lazo social en 'La noche de los visones' y 'La Regine de Aluminios el Mono' de Pedro Lemebel".

${ }^{9}$ Para un análisis de la influencia del SIDA en la conformación del lazo social en relación a esta crónica, ver el artículo mencionado en la nota anterior.
} 
relación entre un cabo, Sergio, y la Regine. El tercer texto, "Atada a un granito de arena", relata la historia entre una travesti y un joven en el litoral de Chile. Este último afectado por la escasez de dinero se prostituye para poder sobrevivir. Finalmente, "Su ronca risa loca" describe de qué manera se desarrolla la prostitución callejera de las travestis en la ciudad de Santiago.

Serán las travestis presentes en los relatos, quienes retratan “...la sexualidad popular y a sus criaturas errantes, como escurridizas especies ante la moral represiva..." (Cangi 53), las que permitan identificar como se genera un trato masoquista. Esto se debe a la relación que desarrollan con los personajes, especialmente cuando es la prostitución el punto de unión entre ellos. Es a través de este oficio que forjan un lazo con un otro en donde la característica principal es el acuerdo entre las partes, necesario antes de realizar cualquier actividad. Un ejemplo es la crónica "Su ronca risa loca", donde el narrador describe cómo la travesti que se prostituye y el cliente deben estipular las condiciones de la relación antes de realizar cualquier tipo de actividad sexual, “... luego de regateos comerciales, por acrobacias y piruetas extravagantes, llegan a un acuerdo, y sellan el trato..." (Lemebel 77).

Independiente de quién se esté prostituyendo (aunque en general es la travesti), se genera un acuerdo ideal donde esta logra ser aceptada como desea, es decir, poder convertirse en el objeto de deseo de un heterosexual. La crónica "Atada a un granito de arena" describe cómo la travesti usa en su beneficio la precaria situación económica de los jóvenes de clase baja para satisfacer este deseo, “... al saber que el péndex anda de vago por el litoral central... [y] que solo quiere que le paguen el vacilón de sus favores erectos..., el verano resplandece para la loca que... se encuentra con esta liquidación de temporada..." (Lemebel 63). La prostitución implica un acuerdo que permite a la travesti suspender la realidad y vivir idílicamente el objeto de su deseo. Es en este sentido que el contrato masoquista se convierte en la herramienta indicada.

Debido a que la prostitución del cuerpo (travesti) es el punto de unión, el dinero será en la mayoría de los casos el medio por el cual se establece el acuerdo. 
A lo largo de las crónicas está constantemente apareciendo esta forma de intercambio, mecanismo que reafirma desde una posición mercantil la precariedad de la vida de las protagonistas de las historias. De esta forma se marca el estrato socioeconómico de quienes aparecen en las crónicas, retratando los problemas de la clase proletaria y de la minoría sexual. La Chumilou es fiel retrato de este hecho, “...su falsa imagen de diva proletaria apechugando con el kilo de pan y los tomates para el desayuno de su familia. Jugándoselas todas en la esquina del maraqueo sodomita..." (Lemebel 18).

El factor económico es determinante en la constitución del acuerdo que hace la travesti con el otro. No solo por el aspecto laboral, sino porque es el dinero el canal que permite legalizar hasta cierto grado el deseo de pertenencia. Es decir, la fantasía de la aceptación se construye a través del contrato produciendo y delimitando la ilusión efímera de legalidad; “... a simple vista confunde al transeúnte que pasa... [el] futuro cliente conoce el teatro japonés de ese maquillaje enyesado, pero igual se deja succionar por su propio engaño..." (Lemebel 77). La función de este "engaño" caracteriza la relación masoquista, la travesti y su contraparte construyen una fantasía que permite suspender la realidad para satisfacer el deseo en el cual se funda el lazo: "Un desvío gay para matar el hambre (dicen ellos)... y a pesar del dolor, él se queda quietito gozando esa dureza (eso nunca lo va a contar)" (Lemebel 64).

Entra en juego la noción de educador que caracteriza al masoquista, este debe generar en el otro la capacidad de construir una fantasía para poder satisfacer su deseo. Como se retrata en el texto de Lemebel en el ejemplo anterior, se genera este juego en donde los roles cambian: no solo la travesti es un hombre (en las crónicas seleccionadas) vestido de mujer, sino que sus amantes deciden (a través del acuerdo) ver el cambio como una alternativa a la realidad. La educación que se concibe en el masoquismo se relaciona entonces con esta intención de cambiar el mundo "real" por uno ideal, en donde se permite la relación que se generan entre ambas partes. Esto, no solo desde la relación (macho)homosexual que es 
parte de la normatividad neoliberal ${ }^{10}$, sino que la relación travesti-hombre. Es a través de esta 'educación' entonces que la travesti persuade al statu quo que lo rodea; educar en la homosexualidad a los "péndex" que vagan por el litoral, para que el "desvío gay” permita producir la fantasía.

Se puede afirmar que en las crónicas el uso del cuerpo como objeto de transacción, además de reflejar la condición socioeconómica de las travestis, también marca una ideología política a través de la voz del narrador. Este describe el (sub)mundo de las travestis proletarias presentes en las historias. Es la voz de representación que relata cada una de las historias y que construye la imagen de la travesti que excluida de las filas marxistas debe optar por adaptarse a las condiciones que la rodean. El masoquismo permite esto, el trato interpersonal suple la exclusión que la afecta. Es por esto que la travesti forja en su fantasía un 'escenario alternativo' en el cual puede establecer lazos que oculten la realidad y educa al otro para hacerlo participe de esto.

Por otro lado, en "La Regine de Aluminios el Mono", la relación que establece la Regine con Sergio da cuenta de cómo en plena dictadura militar la dueña del prostíbulo produce este efecto de ‘suspensión’: “El Sergio se dejó lamer el oído para no escuchar los timbales de la pólvora. Dejó que esa succión, apagara los gritos de mujeres agarradas a los hombres que él arrastraba a culatazos hasta los camiones" (Lemebel 29). La relación masoquista funciona para ambas partes, no solo es la travesti, sino que el otro también satisface su deseo.

\footnotetext{
${ }^{10}$ En El cuerpo agredido de la homosexualidad proletaria y Loco afán de Pedro Lemebel (2010), Diana Palaversich desarrolla este tema. La autora indica que la escritura de Lemebel se opone al concepto globalizador y normativo gay importado de los Estados Unidos y que fue, y es, aceptado por los homosexuales de la clase media Latinoamericana (247). Lemebel es uno de los autores que pone en jaque la visión normativa que busca estandarizar e institucionalizar la homosexualidad en la figura del macho-gay, eliminando las diferentes formas en que puede manifestarse esta condición sexual (como en el travestismo). Profundamente vinculado, esta posición sobre la (homo)sexualidad viene de la mano del neoliberalismo político-económico que hemos heredado en nuestro continente de los países desarrollados, especialmente los Estados Unidos. El autor de Loco afán consiente de este hecho, insiste en relacionar la homosexualidad con los conceptos de clase social, explotación, colonización, que han sido eliminados del discurso neoliberal (Palaversich 247).
} 
En el caso de las crónicas señaladas, siempre es el cuerpo una necesidad para conformar el vínculo. Es por esto que la prostitución facilita la constitución de una relación masoquista, ya que el deseo travesti siempre es mediado a través del cuerpo en las crónicas. Esto porque el autor nos presenta un escenario en donde el deseo travesti de cada uno de sus personajes se basa en sobre-vivir al contexto represivo que lo excluye. Es el cuerpo y su apariencia travestida el que presenta dos cualidades paradójicas en este caso. Por un lado, es el rasgo de la exclusión de la sociedad, pero al mismo tiempo, es la herramienta que tiene para 'adaptarse' a ella a través de la prostitución. Debido al contrato entre dos personas (ya sea explícita como implícitamente), donde se establecen derechos y deberes a los que deben someterse, es que se hace posible que la travesti pueda conseguir la inclusión social. Debido a que el contrato, como fue mencionado anteriormente, funciona como base de las sociedades modernas capitalistas. En el caso específico de esta crónica, la política permite generar que el acuerdo entre las partes se desvincule, hasta cierto punto, del aspecto monetario que suele concretar el lazo. Como se da en la relación que establecen los oficiales del regimiento que acuden al prostíbulo de la Regine: "Solamente la luz del cuarto piso, era un faro para las patrullas cansadas de apalear a la gente en el tamboreo de la represión... el teniente a cargo de la patrulla, mandaba a un pelao donde la Regine a preguntarle si los podía recibir, si podían pasar un rato a descansar los chiquillos" (Lemebel 27).

Este nuevo tipo de transacción no se desvincula de la característica principal de una relación masoquista, mientras la Regine y el resto de las travesti se prostituyen con los militares, éstos otorgan protección a la minoría política y sexual que conforman y que es perseguida en la época dictatorial que contextualiza la crónica. Es el lazo forjado entonces el que logra producir la fantasía de la incorporación social. Este ideal se liga con el pensamiento político del narrador que señala que con la llegada del autoritarismo en Chile se produce la eliminación radical de la aceptación social, por lo que la relación de tipo masoquista se convierte en el único medio de conseguir la inserción social. Por 
otro lado, el matiz ideológico de las crónicas se asocia también con la fiesta de la Palma y la fotografía que recuerda la época anterior al régimen autoritario. Son el testamento de como la UP en Chile permitió la ilusión inclusiva de la minoría travesti, que el narrador asocia directamente a una ideología política específica: “... es quizás el único vestigio de aquella época de utopías sociales, donde las locas entrevieron aleteos de su futura emancipación” (Lemebel 21).

Esta oposición entre los contextos en que se sitúan ambas crónicas, "La noche de los visones" y "La Regine de Aluminios el Mono" (UP y dictadura respectivamente), testifica la posición ideológica de la voz que narra, incorporando el matiz político que influye y genera lazos masoquistas que permiten a las travestis cumplir con la fantasía de la inclusión dentro de la norma social imperante ${ }^{11}$. Recordemos que el homosexual en la sociedad latinoamericana siempre se ha encontrado en una posición estigmatizada, tanto por la rígida organización heterosexual, como por constituirse en el espacio de desecho para una masculinidad hegemónica la cual se reafirma rechazando de forma simbólica a todo lo que no corresponde a los modelos de "lo masculino" (Guerra 107). El estigma de la travesti lemebeliana radica en que no solo es rechazada por lo que indica Guerra, sino que al mismo tiempo la represión de la dictadura hacia la izquierda las afecta de la misma manera, específicamente a las travesti representantes de la clase proletaria (Chumilou, Regine) que se identifican políticamente con el marxismo.

El fragmento que sirve de epígrafe para esta sección permite enfatizar el carácter ideológico de los personajes que protagonizan las crónicas lemebelianas

\footnotetext{
11 El caso del conscripto Pedro Soto Tapia es ilustrativo para este hecho. En el año 1996 es asesinado en un confuso crimen que ha sido asociado a tráfico de drogas y relaciones homosexuales dentro de los cuarteles del ejército de Yungay. Lo significativo de este acontecimiento es que permite reflejar el caso opuesto a lo que señalábamos. Mientras que los travestis están fuera de la norma y buscan a través del lazo masoquista suplir (momentáneamente) esta carencia, en el caso del conscripto Soto Tapia al formar parte de la institución (militar) lo posiciona automáticamente dentro de la norma. Esto permite identificar el lazo como sádico: es parte de la jerarquía heteronormada que estructura este tipo de instituciones. Es por esto que el trato homosexual dentro de los integrantes de la institución deviene en el asesinato del conscripto que amenazaba con hacer público los reiterados abusos sexuales que había sufrido.
} 
y señala al mismo tiempo, apoyándose en el contratexto presente de Senel Paz, la ironía de su marginalización por parte de los representantes del "hombre nuevo"12. En el cuento "El bosque, el lobo y el hombre nuevo", Paz retrata la relación que se produce entre un militante revolucionario y un homosexual en la Habana. El punto que queremos recalcar acá se relaciona con el hecho de que al final de la historia, Diego (el homosexual) debe irse de Cuba debido a los problemas que le ha traído su condición de trasgresor al régimen, “...he tenido problemas con el sistema; ellos piensan que no hay lugar para mí en este país" (Paz 10). A pesar de este hecho, defiende la idea de que la diferencia sexual no debería ser causa de rechazo para una ideología política, en palabras del protagonista: "Los marxistas... no dejarán de caminar con una piedra en el zapato hasta que reconozcan nuestro lugar y nos acepten como aliado, pues, con más frecuencia de lo que se admite, solemos compartir con ellos una misma sensibilidad frente al hecho social" (18).

El lazo imaginario de la política que recubre a los partidos revolucionarios de las características del hombre nuevo rechaza relacionarse con no-heterosexuales. Es por esto que es posible interpretar que tanto Lemebel como Paz buscan reivindicar como entes políticos a la minoría homosexual en sus historias. El gesto de ambos autores radica en que el pensamiento político de los protagonistas no es antagonista con su preferencia sexual. Esta búsqueda de reivindicación no es desde una postura de victimización, sino que al contrario, relatan de qué forma la política puede tener un lugar predominante en la vida de los hombres, indiferente si este es heterosexual o no. El Manifiesto lemebeliano cristaliza este gesto, en donde se reclama por una aceptación en las filas marxistas $\mathrm{y}$, con la ironía que característica del autor, pone en jaque al hombre nuevo al reflejar que son lo mismo.

\footnotetext{
${ }^{12}$ Este concepto fue formulado por Ernesto Guevara y hace referencia al ideal del hombre que es abnegado, dedica su vida a la Revolución. El compromiso social que lo caracteriza le permite subordinar sus ambiciones personales a las necesidades de la patria, es decir: encarna los ideales del pensamiento marxista.
} 


\section{Las dos caras de "La Regine de Aluminios el Mono".}

Eran camionadas de hombres que descargaban su pólvora hirviendo en el palacio de Aluminios el Mono. Noche a noche, había derrame para todos; cazuela de potos en la madrugada para la tropa ardiente. A toda hora, a media noche, al alba, cuando el toque de queda era una campana de vidrio sobre la ciudad, cuando algún grito trizaba esa campana y llovían balas sobre los habitantes. Solamente la luz del cuarto piso, era un faro para las patrullas cansadas de apalear gente en el tamboreo de la represión. Entonces el teniente a cargo de la patrulla, mandaba a un pelao donde la Regine a preguntarle si los podía recibir, si podían pasar a descansar un rato los chiquillos, que traían una botella de pisco y que ella no se preocupara. (Lemebel 27)

En la historia de la Regine se pueden encontrar dos tipos de contrato, por un lado el que desarrollan las travestis que se prostituyen con los militares: un lazo clientista proteccionista entre sujetos pertenecientes a una misma clase social, pero separados por el autoritarismo militar (Rossi 65); por otro lado, la relación que tiene Sergio (uno de los cabos de la compañía que frecuenta el prostíbulo) y la Regine. En ambas se establece un acuerdo entre las partes, al igual que en el resto de las relaciones de tipo masoquista. La exclusión de la norma sexual imperante que afecta a las travestis genera que establezcan un contrato con los militares. A través de este acuerdo logran ser 'insertadas' en la sociedad, es decir, que para sobrevivir en el contexto autoritario que los rodea deben establecer un vínculo con la fuerza armada a cambio de protección. Esta es efectiva por el hecho de que el contrato que se establece es con los 'representantes' de la norma.

“Así, restos de cuerpos o cadáveres pegados al lienzo crespo de las sábanas. Cadáveres de boca pintada enroscados a sus verdugos" (Lemebel 30). El uso de palabras como "cuerpo", "cadáver" y "verdugos" refleja la postura político-ideológica de la voz del narrador, que se manifiesta en el texto en la 
figura de la Regine. Son palabras que contextualizan la situación en que se desarrolla la historia, lo cual permite comprender el porqué del contrato que se establece. Queda en evidencia que la protección de la travesti proviene de la misma institución que la juzga y persigue. Se manifiesta en un sentido perverso la ironía de las travestis proletarias, que por su condición sexual el lazo masoquista es la herramienta que poseen para frustrar (momentáneamente) la marginalidad que las caracteriza.

Por otro lado, la relación que se establece entre Sergio y La Regine difiere completamente. A través de una ideología en común (proletarios marxistas en contra del gobierno militar) se genera una amistad entre los protagonistas. Sergio no es un representante de la institución que busca beneficiarse de los privilegios que esta pueda otorgarles, el deseo de él es no ser parte de ella. Ejemplo de esto lo da el propio narrador, "el Sergio nunca quiso hacer el servicio militar, odiaba a los milicos y estaba en esa solo por obligación" (Lemebel 27). Por su lado, la Regine es la representante de la marginalización de la travesti marxista, es por esto que al mismo tiempo que utiliza el contrato para protegerse, usa el SIDA para contagiar a sus 'hermanos' proletarios que conforman el pelotón: "Parca coliza es en la crónica lemebeliana la encargada de infectar a aquellos entregados al placer coital del ano proletario" (Blanco 75). El uso del cuerpo por parte de la travesti es de esta forma herramienta de trabajo prostibular y arma de lucha ideológica.

Es este uso del cuerpo lo que nos permite inferir que a través del lazo masoquista que conforman las travestis se genera la posibilidad de que puedan ser partícipes fantasmagóricas de la normatividad. Esta idea se complementa con lo expuesto en Masculino/Femenino (1993) de Richard, quien señala que la máscara travesti ("sobreactuación femineizante del posar de lo que no se es" (68)), logra resignificar la copia y la simulación de un original como una crítica (periférica) a la normatividad del modelo establecido, el sistema paterno que asocia al dogma eurocéntrico. Considero que esta afirmación es solo uno de los aspectos de la 'realidad travesti' (la situación descrita en las crónicas) ya que el juego de la travesti que se prostituye funciona como reflejo de los deseos de quienes deciden 
ser participantes de él. Por un lado, la travesti busca la satisfacción de una relación normativa, por lo que la crítica resultante de su performatividad hacia las normas es solo un matiz de la situación. Observamos que a pesar de esto, existe el anhelo travesti de ser aceptado por la sociedad en la que se desenvuelve.

Dime po, a qué le tenís miedo. Qué te pasa. Cuéntame, yo soy tumba. Venga, le dijo el Sergio arrastrándola hasta la ventana, hasta el alfeizar enrojecido por el neón de Aluminios el Mono. Santiago había desaparecido en un mar de alquitrán. A la distancia, resplandores de fogatas desahuciaban la noche de protesta. Detonaciones, disparos y ladridos de perros, rompían el peso plomo del aire. ¿No se da cuenta?, preguntó el Sergio apuntando con los ojos el horizonte insomne por el tamboreo de la balacera. Suena bonito, dijo la Regine con tristeza, podríamos bailarlo. Pero no ando con tacos, y yo bailo solo con tacos. Espérate un poco, voy y vuelvo. Y desapareció al tiempo que un bombazo cortó la electricidad dejando todo oscuro. (Lemebel 28)

En el fragment se nos presenta una contextualización y caracterización del espacio y tiempo en el cual se desarrolla la crónica, la dictadura militar en Chile, donde las travestis se prostituían para obtener la 'protección' de los militares. La alusión al cartel de neón de Aluminios el Mono nos refiere inmediatamente al sector de la Vega Central en uno de los bordes del río Mapocho ${ }^{13}$. El "mar de alquitrán" retrata una ciudad perdida, en la cual los "resplandores de fogata" a la distancia se identifican con las protestas en contra del gobierno militar caricaturizando el ambiente represivo de la ciudad. Es en el prostíbulo de la Regine en donde se logran 'refugiar' las travestis y dan paso al trato con los conscriptos para producir una realidad alterna a la que se vivencia por la ventana. Lucía Guerra señala que en la ciudad, como el espacio símbolo de la modernidad

${ }^{13}$ La Vega Central es uno de los mercados más grandes de Santiago que data de finales del siglo XIX. 
republicana, se define (tanto para el espacio público como el privado) una sociabilidad en la que "lo masculino" y "lo femenino" están regidos por pautas preformativas que marcan la diferencia de sexos a través de los modales, hábitos y el tipo de lenguaje (105). En este sentido, las travestis representan una amenaza en este esquema, por lo que el contrato con los militares (quienes defienden y representan a la institución) es la opción que tiene la Regine y el resto de las travestis de evitar la marginalización (temporalmente).

La actitud de la Regine ejemplifica esto, la intención de bailar al ruido de las detonaciones de bombas, los disparos de las armas y los ladridos de perro representa la intención de la protagonista de evitar confrontarse a la realidad que la rodea. Sin embargo, es al mismo tiempo inevitable sentir la "tristeza" que produce el escenario; es por esto que el acuerdo con Sergio se produce en una primera instancia. La expresión "yo soy tumba" refleja entonces el contrato que se genera entre ambos, donde se origina la complicidad que los caracteriza. Por otro lado, funciona al mismo tiempo como un gesto tragicómico que alude a las muertes acontecidas en manos del ejército, las cuales afectaron directamente a los opositores del régimen. El cliente que acude a los servicios del prostíbulo, acepta las reglas del juego que se genera a través del contrato entre las partes.

En consecuencia, podemos indicar que la relación entre los protagonistas comienza por el punto que tienen en común, el rechazo a la dictadura y a sus representantes. "Fue el único que se quedó con ella después de la dictadura. El único pelao flaco que la Regine apadrinó como su amante oficial, después de pasarle lista a la tropa completa. A las hileras de conscriptos que entraban en su ano marchando vivos. Y salían tocados levemente por el pabellón enlutado del SIDA" (Lemebel 27). Este fragmento da cuenta de la relación que se conformaría con el Sergio y la forma en que la Regine utiliza su enfermedad para defender sus ideales. El contrato que establecen la Regine y Sergio está caracterizado porque tiene la misma condición para ambos. La travesti usa el lazo masoquista para concretar su fantasía de pertenencia y la Regine no es una excepción a esto. Es con Sergio con quien concreta este ideal, es él quien le permite establecer una 
relación 'normal', es decir, una relación que este ilusoriamente dentro de la norma. Sergio por su lado tiene el mismo deseo que la Regine, es por esto que la relación que establecen es platónica. Caracterizada de esta manera no por la no correspondencia por una de las partes, sino que para la "era postsida" el amor platónico es el representante de la imposibilidad de las relaciones sexuales entre una pareja.

En la crónica, las relaciones sexuales que contagian con SIDA representan la herramienta de combate ideológico, por un lado, como también la idea de una relación amorosa platónica que se genera en los personajes. Esto se puede observar en el siguiente ejemplo, "[m]ucho después que pasó la dictadura, el teniente y la tropa iban a entender el amor platónico del Sergio y la Regine. Cuando los calambres y sudores fríos de la colitis les dieran el visto positivo de la epidemia" (Lemebel 30). Desde esta perspectiva, en la era postsida la enfermedad ya no es sólo una carga física por el deterioro crónico del sistema inmunológico, sino que se transforma en un elemento configurador de la manera en que el lazo social se construye. Es por esto que el SIDA determina el tipo de relación entre Sergio y la Regine, y es al mismo tiempo utilizado como 'arma bioideológica'. La lucha ideológica en que se desarrolla la crónica entonces influye directamente en la manera en que se establecen las relaciones entre los personajes.

Las formas de concretar lazos masoquistas en la crónica, ya sea platónico o ideológico, se relacionan con aspectos fundacionales de la historia de Chile en la concepción que se ha desarrollado en torno a la figura del macho. Salazar (1999) señala que formar una familia para el "bajo pueblo" era una ilusión que se había diluido como consecuencia de la instauración del modelo mercantil portaliano (42). Esto produce una diáspora de los hombres que abandonaban a sus familias para poder sobrevivir, dejando a un lado a la mujer y los hijos. Hecho que se relaciona a lo descrito por Montecino (1993) al hablar de qué manera Chile está caracterizado por la ausencia del padre desde la época de la conquista, donde la bastardía atraviesa todo orden social donde "La ilegitimidad jugó un papel esencial en la formación de nuestra sociedad" (Montecino 45). El hombre 
entonces define su "hombría" en "el trabajo físicamente pesado, solitario y riesgoso" (Salazar 43).

Históricamente en Chile, la hombría se ha ligado a la noción de "machismo", donde prevalecen las relaciones entre los pares "camaradas" que con la "compañera de turno" y los hijos (Salazar 48). Este vínculo entre los hombres remite a la noción de homosocial desire desarrollada por Sedgwick (1985), es decir, el deseo (en su sentido libidinal) que se genera en las relaciones entre personas de un mismo sexo. La autora relaciona este concepto con las estructuras patriarcales y señala que la heterosexualidad 'obligada' está construida en el sistema de relaciones en las que el macho domina, produciendo como consecuencia en el sistema patriarcal la necesidad de la homofobia y el matrimonio heterosexual. Se genera entonces (debido a que radica en sus mismas bases estructurales) que una sociedad no pueda erradicar la homofobia, sin concebir un cambio en las estructuras políticas y económicas (Sedgwick 3).

Podemos inferir entonces que la ideología de las travestis en las crónicas permiten reflejar de qué manera la sociedad chilena, especialmente en la dictadura que contextualiza el texto de "La Regine de Aluminios el Mono", se basa en estructuras patriarcales que prohíben las relaciones homosexuales. Presente esto en la marginalización de los protagonistas, se vincula estrechamente en el aspecto ideológico que caracteriza a los personajes proletarios. El carácter económicopolítico se entrelaza con la sexualidad en la Regine, representante de la travesti proletaria que no solo sufre la homofobia de la norma, sino que también la represión ideológica de la dictadura militar.

Por otro lado, estos tres aspectos se presentan en la crónica también en la institucionalidad de la que son representantes los militares que visitan el prostíbulo de la Regine, quienes son el estereotipo del "macho" chileno. La prohibición de la norma de establecer relaciones homosexuales genera una paradoja en estos personajes que van al prostíbulo travesti. Este hecho remarca la cualidad del lazo masoquista, el contrato que constituyen es el medio para poder invalidar (momentáneamente) la norma social imperante y a la vez seguir siendo 
el "macho" en las relaciones que establecen. Señalemos entonces que la homofobia característica de las estructuras patriarcales no desaparece, simplemente es suspendida a través del acuerdo.

\section{En la esquina masoquista}

“... miriadas de jóvenes varones recuestan la rotundez de sus espaldas, a la caza de hombres que paguen por acceder al vericueto del áspero goce que propalan, contra los postes de las grandes ciudades de Occidente". Néstor Perlongher.

A toda lluvia, tiritonas de frío, calentando la espera con un cigarro barato; la noche milonga del travesti es un viaje rápido, un guiño fortuito que confunde, que a simple vista convence al transeúnte que pasa, que se queda boquiabierto, adherido al tornasol del escote que patina la sobrevivencia del engaño sexual. Pero la atracción de esta mascarada ambulante nunca es tan inocente, porque la mayoría de los hombres, seducidos por este juego, siempre saben, siempre sospechan que esa bomba plateada nunca es tan mujer. Algo en ese montaje exagerado excede el molde. Algo la desborda en su ronca risa loca. Sobrepasa el femenino con su metro ochenta, más tacoaltos. La sobreactúa con su boquita de corazón pidiendo un pucho desde la sombra. (Lemebel 77)

En el inicio de esta crónica se nos describe de qué manera se desarrolla la vida prostibular de las travestis en las calles. Notemos de qué forma lo que pertenecía al espacio de lo privado en el prostíbulo de la Regine, se posiciona en el espacio público en este texto. Lo que era en un principio un diseño que 
correspondía a la voluntad moderna y falogocéntrica, paradójicamente permite al mismo tiempo la satisfacción de los instintos denominados ilegítimos (Guerra 111). A pesar de que se genera esta "fuga libidinal", como señala Guerra, esta siempre ocurre en "la noche milonga del travesti" alejado del ojo público de la luz del día y "desde la sombra", hace un llamado al potencial cliente. La ciudad nocturna se constituye entonces como una suerte de protectora para la travesti, donde estos son capaces de trabajar salvaguardados en la oscuridad de la marginalización.

Un retrato de la travesti que "tiritona de frío" espera la llegada de algún cliente, donde el fumar "un cigarro barato" acentúa el rasgo proletario de sus filas. Esta escena nos permite unir dos rasgos que permiten identificar la relación masoquista que se da entre la travesti y el cliente. Como indicamos anteriormente, el engaño juega un rol fundamental en la etapa previa a generarse el vínculo, es a través de este que el cliente es seducido para entrar al juego de la travesti. En el texto encontramos un ejemplo de esto cuando se retrata la espera que hace la travesti de un cliente, mientras los peatones recorren las calles de la ciudad, “... la noche milonga de la travesti es un viaje rápido, un guiño fortuito que confunde" (Lemebel 77). Es esa "confusión" de quien pasa por el prostíbulo callejero el inicio del juego, es lo que permite que el engaño del intercambio de roles que caracteriza a la travesti de resultado y permita un primer acercamiento que de inicio al lazo futuro.

Es el "engaño sexual" el factor que permite al cliente 'heterosexual' no enfrentarse a una realidad considerada abyecta por la norma social. El uso del cuerpo por parte de la travesti para simular un cuerpo culturalmente identificado como femenino es lo que permite entonces representar lo que se desea ser (por parte de la travesti) y lo que se debe desear sexualmente (desde la perspectiva del cliente). El engaño conforma el primer paso a que se genere el contrato.

La descripción que se hace del transeúnte que pasa cerca deja en claro que puede darse cuenta del engaño al cual está siendo seducido. Aceptar este engaño se transforma entonces en establecer una relación entre las partes: "Pero la 
atracción de esta mascarada ambulante nunca es tan inocente, porque la mayoría de los hombres, seducidos por este juego, siempre saben, siempre sospechan que esa bomba plateada nunca es tan mujer" (Lemebel 77). La "inocencia" a la que hace referencia nos indica hasta qué punto el engaño inicial funciona, esto es, es el rasgo que inicia el primer acercamiento que da paso al contrato. Los hombres que son seducidos por este cuerpo, el cual saben que no es el de una mujer, aceptan el juego de roles que el cuerpo travestido les ofrece. Son los hombres que aceptan el intercambio de "un pucho" que les es pedido "desde la sombra" para llegar a un acuerdo, en esta imagen, el cigarro se transforma en la primera transacción que realizan las partes, es la primera "cláusula" del contrato que se busca sellar.

Para llegar a este punto, la función de educador que caracteriza al masoquista es la encargada de entregar las herramientas para la construcción de la 'realidad alterna' en que se puede generar este tipo de relación. Educar en el sentido de generar en el otro la capacidad de construir la fantasía que se busca producir. En este caso, el futuro cliente acepta el "engaño travesti" que se le ha ido presentando en la performance callejera que caracteriza la prostitución. Es en este punto en donde se establece el contrato: el cliente acepta la condición sexual de la travesti para poder saciar su deseo sexual, mientras que la travesti utiliza la prostitución del cuerpo para satisfacer la fantasía de legalidad.

\section{Lo que va quedando de este 'loco afán’ masoquista.}

El enfoque de análisis busca presentar una nueva perspectiva frente a la mirada 'tradicional' con la que se ha estudiado el tema. Esta ha calificado al travesti como representante de un grupo marginal frente a la norma social y que 
en su performance representa una crítica a ésta (como plantea Nelly Richard). Por otra parte, considero que desde la teoría del contrato se complementa esta perspectiva al realizar un análisis de los sujetos. Desde este punto se refleja que la travesti es capaz de usar las políticas socioeconómicas que imperan en las sociedades modernas para producir una fuga en la norma. Es en el intercambio económico (a través de la prostitución, generalmente) que es capaz de establecer una relación contractual que le permite cambiar el arquetipo de 'subalterno'. A través del contrato entonces, se generan normas que regirán la relación entre las partes involucradas de forma paralela a la norma social. Por lo que el uso que la travesti hace de este le permite adaptarse a las condiciones que la rodean.

Lo anterior permite establecer que la travesti finalmente es capaz de adoptar las normas que se le imponen al vivir en sociedad y utilizarlas a su favor. Especialmente, la normatividad sexual será lo que posibilite este hecho debido a que es a través del juego con la sexualidad que caracteriza la enmascarada travesti lo que hace viable que se establezca un lazo masoquista con un otro. En síntesis, la travesti (de las crónicas) ha sido capaz de tomar las leyes de mercado que dominan en la sociedad y travestirlas en su beneficio.

En la escritura de Lemebel el concepto descrito por Sacher-Masoch se renueva. En la obra del alemán, la forma en que se estructura y se genera el contrato está rodeado de formalismos necesarios (escritura y firma de las partes, etc.) para sellar el acuerdo. En Lemebel, la adaptación del contrato yace en el coloquialismo callejero y el uso del cuerpo travestido, los cuales permiten nuevas alternativas para concretar el trato. Los rasgos esenciales para el establecimiento de un acuerdo existe de igual manera que en Sacher-Masoch (esto es, se da entre dos individuos y se rige por normas prestablecidas en el contrato), pero es la forma como se utiliza el lenguaje lo que renueva la manera en que Lemebel presenta este tipo de relación. Pedir un "pucho", por ejemplo, es una frase que se resignifica cuando es enunciada por una travesti en una de las esquinas de Santiago. Las implicancias que tiene permite renovar la forma en que se constituye el contrato entre las partes, donde Lemebel utiliza un lenguaje popular 
para introducir una nueva forma de establecer una transacción (el cuerpo travesti) que deriva en una relación masoquista.

De estos dos puntos, el intento de 'ser como algo' y el uso de conceptos canónicos derivados de autores que derivaron en etimologías y patologías, quiero recalcar un aspecto fundamental en la obra lemebeliana: el punto de unión entre lo culto y lo popular desde el gesto particular que caracteriza al autor. Lemebel se ha constituido como uno de los autores emblemáticos al momento de retratar la sociedad y cultura popular chilena. Pero además, incorpora en sus crónicas temáticas cultas, en el sentido de lo que se considera como el canon clásico literario. Es este es uno de los rasgos más relevantes de su literatura, ya que la confluencia entre las temáticas culto/popular logran fusionarse en sus textos desde su visión particular (travesti marxista) y en la forma en que se constituye su escritura.

\section{Bibliografía}

Blanco, Fernando A. "De los ideales colectivos al sentimentalismo de la primera persona".

Desdén al infortunio. Sujeto, comunicación y público en la narrativa de Pedro Lemebel. Ed. Fernando A. Blanco y Juan Poblete. Santiago: Cuarto Propio, 2010. 71-98. Impreso.

Cangi, Adrián. "La cigarra no es un bicho". Desdén al infortunio. Sujeto, comunicación y público en la narrativa de Pedro Lemebel. Ed. Fernando A. Blanco y Juan Poblete. Santiago: Cuarto Propio, 2010. 45-55. Impreso. 
CATEDRAL Tomada: Revista de crítica literaria latinoamericana / Journal of Latin American Literary Criticism El baile de las que sobran, el contrato como estrategia de adaptación en Loco Afán.

Deleuze, "Coldness and Cruelty". 1967. Masochism. Trad. Jean McNeil. New York: Zone Books, 1991. 7-138. Impreso.

Guerra, Lucía. "Ciudad neoliberal y los devenires de la homosexualidad en las crónicas urbanas de Pedro Lemebel”. Signos Literarios y Lingüísticos Junio 2000: 99-119. Impreso.

Laplanche, Jean y Jean Pontalis. Diccionario de psicoanálisis. 1967. Buenos Aires: Paidós, 2004. Impreso.

Lemebel, Pedro. Loco afán: crónicas de sidario. Santiago: LOM, 1996. Impreso.

Montecino, Sonia. Madres y guachos: alegorías del mestizaje chileno. Santiago de Chile: Cuarto Propio, 1991. Impreso.

Palaversich, Diana. "El cuerpo agredido de la homosexualidad proletaria y Loco afán de Pedro Lemebel". Desdén al infortunio. Sujeto, comunicación y público en la narrativa de Pedro Lemebel. Ed. Fernando A. Blanco y Juan Poblete. Santiago: Cuarto Propio, 2010. 243-65. Impreso.

Pateman, Carole. The Sexual Contract. Palo Alto: Standford University Press, 1988. Impreso.

Paz, Senel. El bosque, el lobo y el hombre nuevo. Sancti Spíritus: Ediciones Luminaria, 1994. Impreso.

Richard, Nelly. Masculino/Femenino: prácticas de la diferencia y cultura democrática. Santiago: Francisco Zegers, 1993. 65-75. Impreso.

Rossi, Alejandro. "Construcción de lazo social en 'La noche de los visones' y 'La Regine de Aluminios el Mono' de Pedro Lemebel". Catedral Tomada 1.2 (2013): 60-68. Web.

Sacher-Masoch, Leopold von. La Venus de las pieles. 1870. Trad. A. González. Buenos Aires: R. Alonso, 1968. Impreso.

Sade, Donatien Alphonse Francoise. Justine o las vicisitudes de la virtud. 1791. Trad. Pilar Calvo. Madrid: Fundamentos, 1976. Impreso.

Salazar, Gabriel. Hombría y feminidad: construcción cultural de actores emergentes. Santiago: LOM, 2002. Impreso. 
Sarduy, Severo. Obra Completa. Madrid: Galaxia Gutemberg, 1999. 1147-1151. Impreso.

Scheff, Thomas J. Emotions, the Social Bond, and Human Reality Part/Whole Analysis. Cambridge: Cambridge University Press, 1997. 73-93. Impreso.

Sedgwick, Eve K. Between Men: English literature and men homosocial desire. New York: Columbia UP, 1993. 1-20. Impreso. 